\title{
The Viral Nature of Massive Open Online Courses (MOOCs) in Open and Distance Learning: Discourses of Quality, Mediation and Control
}

\author{
J. Nyoni \\ Department of Educational Leadership and Management \\ University of South Africa, nyonij@unisa.ac.za
}

\section{Doi:10.5901/mjss.2013.v4n3p665}

\begin{abstract}
Open Access (OA) is one component of a global shift toward openness, participation, transparency and accessibility noted not only in business, government, non-governmental organisations, but in educational sectors as well. Within education, the emergence in some disciplines of the dominance of OA publishing of scholarly papers and articles in OA journals is the most visible evidence of this trend toward massive open online courses (MOOCs). Lifelong learners can now use various tools to build and manage their own learning networks, and MOOCs may provide opportunities to test such networks. This study asynchronously collected data in form of electronic textual discourses from University of South Africa (Unisa), Zimbabwe Open University (ZOU) and University of Botswana (UB) academic staff through the use of the bulletin board system (BBS), and analysed it using a qualitative deconstructive discourse analysis (QDDA) underpinned by a case study design. Trends from MOOC deconstructive discourse analysis (QDDA) indicate that MOOC virality is unstoppable, but there is need to understand how pedagogy and an organisational approach to online and offline learning will lead to improve the quality of mediation outcomes, control and experiences for both students and lecturers.
\end{abstract}

Keywords: Massive open online course (MOOC); virality; Open access; Open and distance learning (ODL); chaos theory

\section{Introduction}

The issue of quality assurance of massive open online courses (MOOCs) is a big challenge for open and distance learning (ODL). In most cases, in comparison with other online courses, MOOCs lack structure, and rarely recognise the central role of the mediator. MOOCs involve largely self-directed learning, which is a very different experience compared to formal education. The virality or viral nature of MOOCs creates a population that is self-selected to be engaged and passionate about this approach to learning. MOOCs demand a certain level of digital literacy from the participants, which has raised concerns on inclusivity and equality of access, particularly in developing states.

Typically, there tends to be little formal quality assurance for MOOCs. It has been suggested that one approach could be for them to be evaluated by students and mediators, leading to league tables that rank the courses by their quality (Daniel 2012). In this way, it is possible that courses from institutions and individuals that rate poorly will either disappear due to lack of demand or will survive by improving course quality in response to poor ratings. Arguably, for MOOCs, the most significant form of quality assurance and enhancement comes from the reflections and informal evaluations of the enthusiasts who produce the courses, and comments from participants using social media (Yuan \& Powell, 2013).

Problems in the schooling system have been transferred to ill-equipped higher education and training and tertiary institutions, which are failing to cope with the increased number of learners and demands for academic support (National Planning Commission 2012). The net effect of the myriad of problems is a system that is not able to produce the number and quality of graduates demanded by the country (National Planning Commission 2012). In order to cope with high volumes of ODL students who require skills and/or re-skilling, the Open University (OU) in the United Kingdom is implementing a range of MOOCs, in educational technology, language, learning skills and learning design, as from 2013. These adopt different approaches, for instance, some are elements of existing courses and others are delivered as part of a research programme. They will use a range of technologies and support models. A university-wide strategy will be informed by these early MOOCs, in addition to the existing experience of the Open Learning team. This approach goes some way to ameliorate the effects of external forces and to engage with the MOOC movement.

On the other hand, the University of South Africa (Unisa), in collaboration with its partners in Europe, is attempting to launch MOOCs, and invariably other regional partners in the Sub-Saharan region will eventually join the initiative. The net implication for MOOCs' virality is to understand how pedagogy and organisational approach will lead to control by 
individual ODL modular developers and/or lecturers, quality and control. The question that motivated this study was:

What are the thoughts of open and distance learning (ODL) academics on the virality of massive open online courses (MOOCs) in terms of open access (OA) and its impact on modular quality, mediation and control?

\section{MOOCs' Information Communication Technology (ICT) Logistical Preparedness}

Linked to the logistics challenge is the state of the information and communication technology (ICT) sector. Growth in South Africa's ICT sector has not been accompanied by a realisation of the primary policy objectives of affordable access for all, to the full range of communications services that characterise global economies. South Africa has lost its status as a continental leader in internet and voice connectivity, and its place on global ICT indices has also been usurped by formerly comparable countries, such as Malaysia, Turkey and Korea (DBSA 2011).

Whereas Korea and South Africa were comparatively placed on ITU ratings 15 to 20 years ago, Korea is now a top global performer (Gillwald, 2011). South Africa's ranking on the ITU ICT Development Index has slipped from 72nd in 2002, to 92nd in 2008 (DBSA 2011). While ICT is driven primarily by private investment and private operators, it is guided by national regulatory frameworks which, judged on the basis of their outcomes, have not proven to be particularly effective. Distance education, aided by advanced information communication technology, will play a greater role in expanding learning opportunities for different groups of learners and promote lifelong learning and continuous professional development.

South Africa envisages an increase in the participation rate at universities by at least 70 percent by 2030 , so that enrolments would increase to about 1.62 million from 950000 in 2010. South Africa also proposes to expand the use of distance education. The advances in ICT can help overcome the infrastructure limits to further expansion of higher education. Upfront investment is needed in technology, curriculum design, quality assurance and monitoring. The Department of Higher Education and Training has published a draft policy statement intended to provide a framework for expanding the use of distance education in higher education. The fact that Unisa is perceived as one of the mega ODL institutions in Africa and the world, implies that sub-Saharan ODL institutions would prefer partnering with it in rolling out MOOCs.

\section{Theoretical Framework}

Chaos theory and the sciences of complexity can assist the understanding of the current present systems of education, including (a) when each is ready for transformation, and (b) the system dynamics that are likely to influence individual changes that are designed, and the effects of those changes (Reigeluth, 2004). What are chaos theory and the sciences of complexity? Some of the key features of chaos theory and the sciences of complexity include co-evolution, disequilibrium, positive feedback, perturbance, transformation, fractals, strange attractors, self-organisation and dynamic complexity (Reigeluth, 2004). The study utilised one component of these key features of chaos theory, namely, selforganising systems, to understand the implications of en-masse rolling out of MOOCS by ODL institutions, particularly as regards mediation or facilitation processes, the overall control of intellectual properties and ownership, as well as the sharing of overhead costs.

\section{Self-Organising Systems}

Self-organising systems are adaptive, they evolve and they are agile (McCarthy 2003). They require two major characteristics: openness and self-reference (Wheatley 1999). To be open with its environment, a system must actively seek information from its environment and make it widely available within the system. The intent of this new information is to keep the system off-balance, alert to how it might need to change. An open organisation doesn't look for information that makes it feel good, that verifies its past and validates its present. It is deliberately looking for information that might threaten its stability, knock it off balance, and open it to growth. (Wheatley, 1999:83).

But the system must go beyond seeking and circulating information from its environment; it must also partner with its environment. As Wheatley (1999:84) notes: "Because it partners with its environment, the system develops increasing autonomy from the environment and also develops new capacities that make it increasingly resourceful." A second characteristic of self-organising systems is the ability to self-reference on the core ideas, values, or beliefs that give the organisation an identity. In this way, "[w]hen the environment shifts and the system notices that it needs to change, it always changes in such a way that it remains consistent with itself. ... Change is never random; the system will not take off in bizarre new directions" (Wheatley, 1999:85). 
A third characteristic is freedom for people to make their own decisions about changes. Jantsch (1980:40) has noted the paradoxical but profound systems dynamic: "The more freedom in self-organization, the more order" (as cited by Wheatley, 1999:87). As long as the freedom is guided by sufficient self-reference, it will allow changes to occur before a crisis point is reached in the system, thereby creating greater stability and order. Paradoxically, the system is "less controlling, but more orderly" by being self-organising (Wheatley, 1999:87). Typically, co-evolution occurs through selforganisation, but complex system dynamics have a powerful influence on self-organisation and any resulting systemic transformation.

\section{The Massive Open Online Course (MOOC) in Context}

The term "MOOC" was coined by Dave Cormier and arose after his analysis of one of the first MOOCs, the Connectivism and Connected Knowledge course (known as CCK08) run by George Siemens and Stephen Downes. Other early pioneers include David Wiley and Alec Couros, both of whom ran open versions of campus courses, whereby a course with fee paying students who have access to the course instructor, was made available to anyone to participate, but without the direct support and assessment of a tutor or lecturer (Weller \& Anderson, 2013).

The early experimentation led to more mainstream adoption of MOOCs, and in 2011 two Stanford professors offered an open course in Artificial Intelligence, which attracted over 100,000 students. This was followed by Harvard and MIT announcing a joint initiative to offer open courses, called EdX. In addition, the Stanford team founded a commercial enterprise, Udacity, to offer open courses, and a number of universities offered courses with another private sector partner - Coursera. MOOCs have been trumpeted as having the potential to instigate wide scale and disruptive change in higher education, with Shirky (2012) suggesting they will have the same impact on education as the Moving Picture Experts Group Layer-3 Audio (acronym: MP3) format had on music. He sees MOOCs as highly disruptive for higher education, arguing that "The possibility MOOCs hold out isn't replacement; ... The possibility MOOCs hold out is that the educational parts of education can be unbundled. MOOCs expand the audience for education from current campus students to people ill-served or completely shut out from the current system". For the Open University, MOOCs represent both a challenge and an opportunity. As a purely distance education institution it is arguably more vulnerable to their threat. If learners can study for free, the argument goes, then why would they pay for an education that isn't campus based?

In December 2012, the OU announced the launch of Future Learn, a separate company founded by the OU in consortium with a range of UK universities, to provide MOOCs on a global platform (http://futurelearn.com). This represents a significant investment in terms of resources, finances and brand in MOOCs, which highlights their resonance with the OU's core functions.

\section{Transformation of Mediation Tools in Open and Distance Learning (ODL)}

Transformation of teaching and learning requires careful exploitation of technologies, a deep understanding of teaching and learning, and expertise in the content area being delivered. Time will tell if we really are developing new approaches to teaching and learning or are in fact returning to models associated with past generations. To realise the potential of recent developments, Garrison and Archer (2007) are clear that new research and theory development is needed to "...explain, interpret, and shape the new forms of educational practice that have been made possible by highly interactive communications technologies" (2007:77). Yet we still need to draw from scholarship that provides foundations for distance education as a field of inquiry, recognises the field's central underpinnings of access and equity, and highlights the importance of recognising individuals and working to individualise the distance learning experience. Garrison (1989) and Harasim (1989) produced work that informed these developments. Other distance educators such as Tait (1988), Rumble (2000), and Simpson (2000) drew attention to the need for student support. Evans (1994) and Gibson (1998) both undertook work that focused attention on the characteristics and needs of distance students. Kramarae (2007); Kirkup and Von Prümmer (1990) highlighted issues of gender disparity. More recently, the intensified interest in pedagogy has been reflected in the work of Anderson and Dron (2011) who extended the generations framework by introducing the concept of generations of pedagogy. Work such as this remains central to the field. Evans and Nation (2007) say our current challenge is to resist what they see as a trend to adopt "old industrial approaches to distance education re-jigged into online forms" (2007:653). They urge us to address the challenges of constructivism and move our still conventional institutions to embrace online teaching and learning seriously. Distance education operations have evolved through the following four generations: first, the Correspondence Model based on print technology; second, the Multi-media Model based on print, audio and video technologies; third, the Tele-learning Model, based on applications of 
telecommunications technologies to provide opportunities for synchronous communication; and fourth, the Flexible Learning Model (FLM) based on online delivery via the internet.

Although many universities are just beginning to implement fourth generation distance education initiatives, the fifth generation is already emerging based on the further exploitation of new technologies.

\section{Learner Adaptability to Digital Migration in ODL}

Adaptive instruction is not new. A form of it has existed since the days of Socrates. Since at least the 1980s, education researchers have viewed adapting instruction to students as a major factor in successful learning (Corno \& Snow, 1986). By that time, research had demonstrated the power of one-on-one tutoring, in which the tutor adapts learning experiences and the time provided for learning to the needs of the individual student (Bloom, 1984).

Digital learning systems are considered adaptive when they can dynamically change to suit the learner better in response to information collected during the course of learning rather than on the basis of pre-existing information such as a learner's gender, age, or achievement test score. Adaptive learning systems use information gained as the learner works with them to vary such features as the way a concept is represented, its difficulty, the sequencing of problems or tasks, and the nature of hints and feedback provided.

Adaptive instruction is related to individualised, differentiated and personalised learning. Minimally adaptive learning systems offer individualised pacing, whereas more sophisticated systems differentiate the nature of learning activities based on student responses. Systems are now being developed to support personalised learning by incorporating options for varied learning objectives and content as well as method and pacing of instruction.

Teachers tend to vary learning approaches between classrooms serving students with different levels of prior achievement (Oakes, 2005). Differentiating teaching within a classroom requires considerable effort and skill on the part of teachers and also a wide variety of resources spanning different levels of difficulty. When differentiation does occur within a classroom, it typically involves separating students into two or three groups based on skill fluency or degree of prior knowledge (Fuchs, Fuchs \& Vaughn, 2008).

In computer-based instruction, adapting the pace of introducing new material to individual learners began in the 1980s. Such mastery-based learning approaches were common in the learning systems many school districts used in those years with low-achieving students or students at risk. These systems provided instruction on sequences of skills, with the requirement that each student master a given skill before working on the next one. Although they adapted the amount of time a student spent learning material to the individual student's needs, these mastery learning programmes still exposed all students to the same material presented in the same way.

Table 1: Chaos surrounds the meanings of Individualised, Differentiated and Personalised Instruction (Nyoni, 2012)

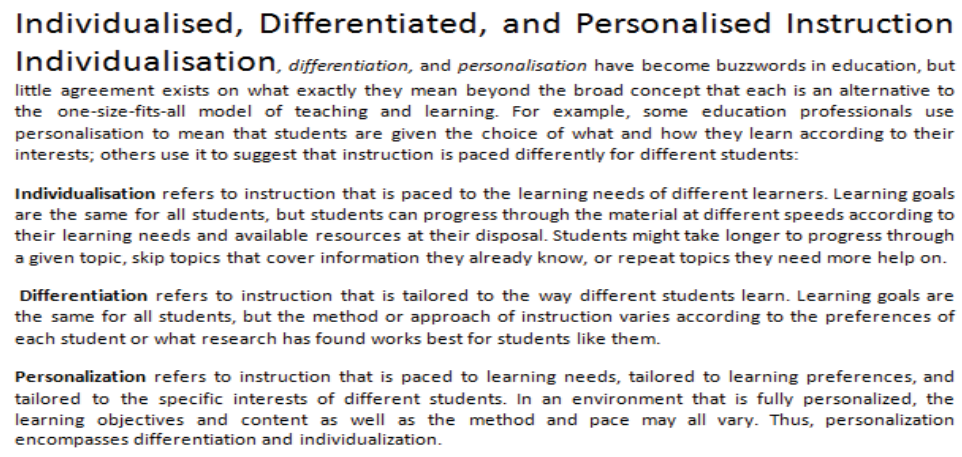

Individualized, Differentiated, and Personalized Instruction Individualization, differentiation, and personalization have become buzzwords in education, but little agreement exists on what exactly they mean beyond the broad concept that each is an alternative to the one-size-fits-all model of teaching and learning. For example, some education professionals use personalization to mean that students are given the choice of what and how they learn according to their interests; others use it to suggest that instruction is paced differently for different students. In this report, we use the definitions from the National Education Technology Plan (US Department of Education 2010a):

Individualisation refers to instruction that is paced to the learning needs of different learners. Learning goals are the same for all students, but students can progress through the material at different speeds according to their learning 
needs. Students might take longer to progress through a given topic, skip topics that cover information they already know, or repeat topics they need more help on.

Differentiation refers to instruction that is tailored to the way different learners learn. Learning goals are the same for all students, but the method or approach of instruction varies according to the preferences of each student or what research has found works best for students like them.

Personalisation refers to instruction that is paced to learning needs, tailored to learning preferences, and tailored to the specific interests of different learners. In an environment that is fully personalised, the learning objectives and content as well as the method and pace may all vary. Thus, personalisation encompasses differentiation and individualisation.

\section{Methodological Underpinnings}

Amid chaos, confusion and uncertainties triggered by the virality of MOOCs, qualitative deconstructive discourse analysis (QDDA) employed a critical attitude toward the meanings permeating the asynchronously generated data and toward the researcher's own beliefs. Its essence is captured in MacLure's (2003:3) argument that our common-sense beliefs about educational realities (MacLure, 2003:9, 171-173) should be deconstructed and torn apart to enable proper engagement with the discursive educational realities (MacLure, 2003:4). The third method, internal criticism, helps in systematic and comprehensive analysis of the textual materials examined in this critique. Bell (1999:113-116) suggests that internal criticism could be used in critically analysing the contents of text in terms of the following: its genre; the language it employs; the author's background and experiences; the purpose, background, reliability of the document, etc. Case studies are often used to study large-scale phenomena, such as entire development projects (Bratthall \& Jørgensen, 2000; Bratthall et al. 2000; Leszak, Perry, \& Stoll, 2000). In this study the case included three universities in sub-Saharan Africa, namely, Unisa, ZOU and UB, because the three of them are situated in sub-Saharan Africa and offer tuition at a distance. I asynchronously collected data in the form of electronic textual discourses from the stated academic staff through the use of the online bulletin board system (OBB) over a period six months, and analysed it using qualitative deconstructive discourse analysis (DDA) underpinned by a case study design.

Table 2: Categorisation of participants per site

\begin{tabular}{|c|c|c|c|}
\hline Institution & Unisa & University of Botswana & Zimbabwe Open University \\
\hline Participants & 10 & 4 & 6 \\
\hline Entries & 360 & 153 & 210 \\
\hline
\end{tabular}

However, knowledge bound to people is not replicable (Burgess, 1988:232). This may require the researcher to raise the abstraction level of the case study (Denzin \& Lincoln, 1998:193), which could make the case study less interesting for practitioners. However, triangulation is a compelling approach as it compresses the lead-time needed to study a phenomenon and does not require multiple cases.

\section{Findings, Discussion, Recommendations and Conclusion}

Chaos theory offers an explanation as to why some innovations disrupt existing stable educational good practices to the advantage of incumbent practices. In this study, this is a significant question for ODL higher education institutions to address: online teaching innovations, such as MOOCs, herald a change in the education landscape that poses a threat to the existing models of provision of degree courses. If this is the case, then chaos theory innovation suggests that there is a strong argument for establishing an autonomous research unit to offer an appropriate response to these potentially disruptive innovations.

In line with chaos theory, the study indicated that there are concerns about the pedagogy and quality of current MOOC courses, with a clear distinction between process and content-based approaches. The study asynchronously collected data in form of electronic textual discourses from the stated academic staff through the use of the bulletin board system (BBS) and analysed it using a qualitative deconstructive discourse analysis (DDA), underpinned by a case study design. The findings clearly articulate some of the concerns as raised by ODL practitioners from the HE institutions in sub-Saharan Africa.

The debate centred on the knowledge of MOOCs by the lecturers who volunteered their participation through BBS. Findings indicated that MOOCs were a new phenomenon that, however, invariably will impact on the work of ODL lecturers. The moderator used the following question to analyse how informed lecturers were in terms of the virality of 
MOOCs as platform for open access (OA):

What are the thoughts of open and distance learning (ODL) academics on the virality of massive open online courses (MOOCs) in terms of open access (OA) and its impact on modular quality, mediation and control?

\subsection{Lecturers' thoughts on MOOCs}

The moderator started by determining whether lecturers were familiar with MOOCs in their work space, and the following were common responses:

\subsubsection{Common responses from the three site participants:}

As far as I know, so say most of the people, MOOCs are the new thing in ODL, an approach
being hyped in certain quarters but not sure whether it's a mediation tool or not! I only read
about the World Bank's new pilot initiative in Tanzania that is seeking to incorporate
Coursera offerings as part of a broader initiative to help equip students with market-relevant
IT skills. 12 June 2012 10:45:00 PDT

A massive open online course (MOOC) appeared to be a new and unique phenomenon in the field of ODL pedagogy, and a large number of mediators or lecturers seem to be trying to understand its virality and how it will impact on their operations. MOOCs are a recent development in distance education and often use open educational resources and thus will have an impact on ODL pedagogy. The majority of the participants indicated that they heard about MOOCs through the media. Prompted further, though their postings, to explain whether they knew of any MOOCs providers, they came across with the following common comments:

\subsubsection{Common responses from the three site participants:}

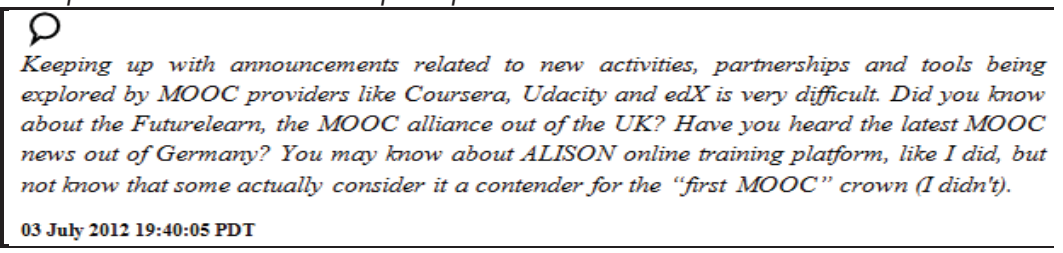

The co-founder of Coursera, one of the largest and best-known MOOCs (the two other leaders in this space are Udacity and edX) stopped by the World Bank to talk about what Coursera is doing, and learning. Coursera (www.coursera.org), edX (www.edx.org), Udacity (www.udacity.com) and Khan Academy (www.khanacademy.org) are some of providers identified by the participants. They are seen as models for delivering quality educational content at no cost to any willing learner. While MOOCs have enrolled students from developing countries pretty much from the start, there have not yet been many attempts to include MOOCs systematically as part of targeted education efforts in low income countries in sub-Saharan Africa. The study indicated that most lecturers had little knowledge about who provides MOOCs.

Pedagogy

From a pedagogical point of view, MOOCing - learning through MOOCs - is basically self-organised learning, the most interesting form of education. Will it be possible for the MOOC movement to substantially push forward the vision of self-organised, autonomous lifelong learners? Will they be able to navigate a stream of learning opportunities with massive crowds, toward a bright future with enriched skill sets and all the urgently needed competences for the knowledge society?

\subsubsection{Common responses from the three site participants:}

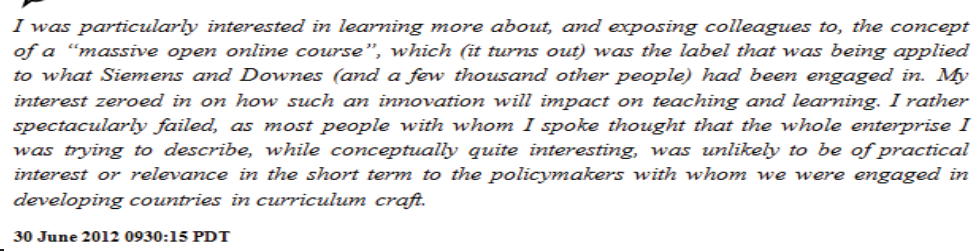


With such support, MOOCs provide a great opportunity to develop new pedagogy. In a world of abundant content, courses can draw from a pool of open educational resources (OER) and provide their students with better and more varied teaching than individual instructors could develop by themselves. MOOCs are seen as a game-changer for traditional universities and ODL alike.

\subsection{MOOCs and intellectual property: ownership and use rights}

Higher education should pause and reflect on these restrictive licensing terms and the implications for the academic enterprise that has been traditionally built on creating and sharing knowledge as a core value of the teaching and learning mission. In today's remix learning culture, what does it mean when users have to give up their IP rights to participate in a MOOC? When sharing is restricted? The licenses show that these companies are quite proprietary about the rights for use of their content, but are broadly sweeping in claiming rights for user-generated content. MOOC licenses, to date, are blurring the lines between traditional educational values and the commercial enterprise. These are some of the challenging issues that colleges and universities need to consider as MOOCs become more pervasive. Looking at the Terms of Service for Coursera, edX, and Udacity revealed some licensing language that colleges and universities should be cognizant of when contemplating joining an MOOC.

\subsection{MOOCs and the quality question}

Quality in online learning can be defined in many ways: quality of content, quality of design, quality of instructional delivery, and, ultimately, quality of outcomes. On the face of it, the organising principles of MOOCs are at odds with widely observed good practices in online education. Many of the first MOOCs are providing quality of content, but are far behind the curve in providing quality of design, accountable instructional delivery, or sufficient resources to help the vast majority of students achieve a course's intended learning outcomes. While no-one questions the quality of instruction offered by some of the finest minds in higher education, it is reasonable to question the extent of student learning from MOOCs. Few participants complete the course they enrol for. Of this very small percentage, questions remain about the validity of the assessment instrument, the security of the assessment process, and, in some cases, the identity of the participant. To date, there is very little evidence of actual learning done by students who enrol in an MOOC.

\subsection{Recommendations}

MOOCs provide a great opportunity to develop new pedagogy. In a world of abundant content, courses can draw from a pool of open educational resources (OER) and provide their students with better and more varied teaching than individual instructors could develop by themselves (Bates 2012).

\subsection{Conclusion}

Lecturers interviewed in this study see MOOCs as a disruptive innovation that will transform higher education in general and ODL mediation processes in particular (Shirky 2012). To them, MOOCs provide a powerful tool to make fundamental, albeit chaotic, changes in the organisation and delivery of ODL over the next decade or even beyond. However for ODL leadership, MOOCS help address the problem of institutional budget constraints and help to reduce the cost of degree courses by enabling inexpensive, low-risk experiments in different forms of ODL provision (Carey 2013). Commercial organisations see MOOCs as a way to enter the ODL market by providing an MOOC platform and developing partnerships with existing institutions and to explore new delivery models. Two common reactions dominated the bulletin board system (BBS) discussion amid chaos and confusion: 1) fear that MOOCs will disrupt and devalue the current education system 2) growing excitement over the spreading hype surrounding fully online and fully distributed learning using modern technologies. In this study, I wish to strike a middle ground, arguing that MOOCs make lecturers re-think their teaching in ways that ultimately will enhance, not replace, classroom learning. The chaos theory provides opportunities for lecturers to adapt ODL methodology in order to reach out to a large pool of today's students who are, largely becoming, digital generations.

\section{References}

Anderson, B \& Simpson, M. (2012). History and heritage in open, flexible, and distance education. Journal of Open, Flexible and Distance Learning 16(2):1-10. 
Anderson, T \& Dron, J. (2011). Three generations of distance education pedagogy. International Review of Research in Open and Distance Learning 12(3). Retrieved from http://www.irrodl.org/index.php/irrodl/article/view/890/1826 [accessed on ???]

Bates, T. (2012). What's right and what's wrong about Coursera-style MOOCs? http://www.tonybates.ca/2012/08/05/whats-right-and-whatswrong-about-coursera-style-moocs/ [accessed 2012-09-22]

Bates, T. (2013). Harvard's current thinking on MOOCs, http://tinyurl.com/a2uh86z [accessed: 28 June 2013]

Bell, J. (1999). Doing Your Research Project: a guide for first-time researchers in education and social Science. 3rd ed. Buckingham: Open University Press.

Bloom, B. S. (1984). "The 2 Sigma Problem: The Search for Methods of Group Instruction as Effective as One-to-One Tutoring." Educational Researcher 13(6) (June 1):4-16.

Bratthall, L., \& Jørgensen, M. (2000). A Cost/Benefit Analysis of Project Lead-time Impact Factors in a Financial Systems Company—A Longitudinal Case Study. Oslo University, Department of Informatics, Technical Report 291. ISBN 82-7368-240-4.

Bratthall, L., Runeson, P., Adelswa“ rd, K., \& Eriksson, W. (2000). A Survey of Lead-time Challenges in the Development and Evolution of Distributed Real-time Systems. Information and Software Technology, 42(13): 947-958.

Burgess, R. C. (1988). (ed.) Studies in Qualitative Methodology—Conducting Qualitative Research. London, United Kingdom: Jai Press Inc.

Carey, K. (2013). Obama, Rubio Agree on One Thing: Technology Could Fix the Higher Ed Mess, http://tinyurl.com/cogw2kh [accessed: 22 June 2013

Corno, L., \& Richard E. S. (1986). "Adapting Teaching to Individual Differences Among Learners." In Handbook of Research on Teaching, ed. M. C. Wittrock. Washington, DC: American Educational Research Association.

Daniel, J. (1996). Mega-universities and knowledge media: Technology strategies for higher education. London: Kogan Page.

Development Bank of Southern Africa (2011b) Pretoria

Denzin \& Lincoln (1998). Eds. The Landscape of Qualitative Research: Theories and Issues. Thousand Oaks, CA and London: Sage.

Evans, T. (1994). Understanding learners in open and distance education. London: Kogan Page.

Fuchs D, Compton D. L, Fuchs L.S, Bryant J, Davis N.G., (2008). Making "secondary intervention" work in a three tier responsiveness-tointervention model: Findings from the first grade longitudinal reading study of the National Research Center on Learning Disabilities. Reading and Writing Quarterly: An Interdisciplinary Journal. 21(4):413-436.

Futurelearn. (2013) Futurelearn launches, http://futurelearn.com/feature/futurelearn-launches/ [accessed: 09 May 2013]

Garrison, D R \& Archer, W. (2007). A theory of community of inquiry. In Handbook of distance education. 2nd edition. Edited by MG Moore. Mahwah, NJ: Lawrence Erlbaum Associates: 77-88.

Garrison, D. R. (1989). Understanding distance education: A framework for the future. London: Routledge.

Gibson, C. C. (1998). The distance learner in context. In C. C. Gibson (Ed.), Distance learners in higher education (pp. 113-125). Madison, WI: Atwood.

Gillwald, A. (2011). Telecom SNARFU all our own fault, Mail \& Guardian 13 July.

Harasim, L. M. (1989). On-line education: a new domain. In R. Mason and A. Kaye (Eds.) Mindweave: Communication, computers and distance education (p. 50-62). Oxford: Pergamon Press.

Jantsch, E. (1980). The Self-Organizing Universe. Oxford: Pergamon.

Kirkup, G \&Von Prümmer, C.1990. Support and connectedness:The needs of women distance education students. Journal of Distance Education $5(2): 9-31$

Kramarae, C. (2007). Gender matters in online learning. In Handbook of distance education. 2nd edition. Edited by MG Moore. Mahwah, New York: Lawrence Erlbaum Associates :169-180.

Leszak,M., Perry, D.E., \& Stoll, D. (2000). A Case Study in Root Cause Defect Analysis". In: IEEE Computer Society. (ed.) Proceedings. 22nd Int'l Conference on Software Engineering, pp. 428-37. Limerick, Ireland.

MacLure, M. (2003). Discourse in Education and Social Research. Buckingham: Open University Press.

McCarthy, M. P. (2003). Agile business for fragile times: Strategies for enhancing competitive resiliency and stakeholder trust. New York: McGraw-Hill.

Republic of South Africa (2012) National Planning Commission, Pretoria

Oakes, J. (2005). Keeping Track: How schools structure inequality, Second Edition. New Haven, CT: Yale University Press.

Reigeluth, C. M. (2004) Chaos theory and the Sciences of Cmplexity: Foundations for transforming Education. Indiana University

Rumble, G. (2000). Student support in distance education in the 21st century: Learning from service management. Distance Education 21(2): 216-235.

Shirky, C. (2012). Napster, Udacity and the Academy. Available at: http://www.shirky.com/weblog/2012/11/napster-udacity-and-the-academy/. Accessed 6th December 2012.

Simpson, O. (2000). Supporting students in open and distance learning. London: Kogan Page.

Tait, A. (1988). Democracy in distance education and the role of tutorial and counselling services. Retrieved from http://www.c3l.unioldenburg.de/cde /support/readings/tait88.pdf [accessed: 01 September 2013]

Taylor, J. (2001). Fifth generation distance education. Retrieved from http://citeseerx.ist.psu.edu/viewdoc/download?doi $=10.1 \cdot 1 \cdot 113.3781 \&$ rep=rep1\&type =pdf. [accessed: 10 may 2012]

US Department of Education (2010) Evaluationof Evidence-based Practices in Online Learning: A Meta-Analysis and Review of Online Learning Studies. Washington DC: US Department of Education. http://www2.ed.gov/rschstat/eval/tech/evidence-based-practices/finalreport.pdf

Weller, M. \& Anderson, T. (2013). Digital Resilience in Higher Education. European Journal of Open, Distance and e-Learning 16 (1):53 - 66.

Wheatley, M. (1999). Leadership and the New Science: Discovering Order in a Chaotic World. San Francisco, Berrett-Koehler Publishers

Yuan, L. \& Powell, S. (2013). MOOCs and Open Education: Implications for Higher Education. A White Paper. JISC CETIS, http://publications.cetis.ac.uk/wp content/uploads/2013/03/MOOCs-and-Open-education.pdf 